\title{
Evaluating Light Rain from Satellite- and Ground-Based Remote Sensing Data over the Subtropical North Atlantic
}

\author{
JÖRG BURDANOWITZ, LOUISE NuIJENS, AND BJORN STEVENS
}

Max Planck Institute for Meteorology, Hamburg, Germany

\section{CHRISTIAN KLEPP}

\begin{abstract}
Climate System Analysis and Prediction/Center for Earth System Research and Sustainability,
\end{abstract} University of Hamburg, Hamburg, Germany

(Manuscript received 12 June 2014, in final form 5 January 2015)

\begin{abstract}
Three state-of-the-art satellite climatologies are analyzed for their ability to observe light rain from predominantly shallow, warm clouds over the subtropical North Atlantic Ocean trade winds (1998-2005). HOAPS composite (HOAPS-C), version 3.2; TMPA, version 7; and GPCP 1 Degree Daily (1DD), version 1.2, are compared with ground-based S-Pol radar data from the Rain in Cumulus over the Ocean (RICO; winter 2004/05) campaign and Micro Rain Radar data from the Barbados Cloud Observatory (2010-12). Winter rainfall amounts to one-third of annual rainfall, whereby light rain from warm clouds dominates. Daily rain occurrence and rain intensity during RICO largely differ among the satellite climatologies. TMPA best captures the frequent light rain events, only missing $7 \%$ of days on which the S-Pol radar detects rain, whereas HOAPS-C misses $33 \%$ and GPCP 1 DD misses 56\%. Algorithm constraints mainly cause these differences. In HOAPS-C also few available passive microwave (PMW) sensor overpasses limit its performance. TMPA outperforms HOAPS-C when only comparing nonmissing time steps, yet HOAPS-C can detect rain for S-Pol rain-covered areas down to $2 \%$. In GPCP 1DD's algorithm, the underestimated rain occurrence derived from PMW scanners is linked to the overestimated rain intensity, being constrained by the GPCP monthly satellite-gauge combination, whereby IR sensors determine the timing. Algorithm improvements in version 1.2 increased the rain occurrence by $50 \%$ relative to version 1.1. In version 7 of TMPA, algorithm corrections in PMW sounder data largely improved the rain detection relative to version 6. TMPA best represents light rain in the North Atlantic trades, followed by HOAPS-C and GPCP 1DD.
\end{abstract}

\section{Introduction}

Global monitoring of precipitation with high spatiotemporal coverage is only achievable using satellite-based remote sensing. Polar-orbiting passive microwave (PMW) satellite sensors are the basis of all existing satellite-based precipitation climatologies (Kidd and Huffman 2011). PMW sensors are constrained by large footprints of the order of $10-50 \mathrm{~km}$ and infrequent sampling of typically two to four times daily. As a consequence, small-scale showers and precipitation of low intensity are particularly challenging to measure. This work aims at evaluating the representation of precipitation from small-scale

Corresponding author address: Jörg Burdanowitz, Max Planck Institute for Meteorology, Bundesstraße 53, Hamburg, Germany. E-mail: joerg.burdanowitz@mpimet.mpg.de showers in three state-of-the-art satellite climatologies by comparing with ground-based remote sensing over the North Atlantic Ocean trade winds.

We select three satellite climatologies that use Special Sensor Microwave Imager (SSM/I) as a main data source. However, the three climatologies differ in their retrieval algorithms, and they use different additional data sources. Global Precipitation Climatology Project (GPCP) is a widely used global precipitation dataset, available at monthly (Adler et al. 2003), pentad, and daily (Huffman et al. 2001) resolution. The GPCP 1 Degree Daily (1DD), version 1.2 (v1.2), starts at October 1996 and is consistent with the monthly GPCP Satellite-Gauge (SG) product. The nonglobal Tropical Rainfall Measuring Mission (TRMM) Multisatellite Precipitation Analysis (TMPA; Huffman et al. 2007), version 7 (v7), has been available since 1998, incorporating data from the first spaceborne 
precipitation radar (PR). Both GPCP and TMPA are largely based on the Goddard profiling algorithm (GPROF; Kummerow et al. 2001, 2011), a physical retrieval that relates vertical hydrometeor profiles, brightness temperatures, and precipitation rates. In contrast, Hamburg Ocean Atmosphere Parameters and Fluxes from Satellite Data (HOAPS; Andersson et al. 2010) uses exclusively SSM/I data for its precipitation retrieval, available since 1987. Based on a neural net approach, HOAPS performs fairly well in detecting light precipitation within high-latitude North Atlantic cyclones when evaluated against ship-based in situ disdrometer snowfall measurements (Klepp et al. 2010) and weather observations of rainfall from voluntary observing ships (Klepp et al. 2003). Apart from monthly mean precipitation (Andersson et al. 2011), no detailed evaluation of the gridded 6-hourly HOAPS composite (HOAPS-C) has been carried out in the subtropics, which because of the prevalence of shallow clouds and light rain is the focus region for this study.

In the subtropics, satellite sensors are mainly confronted with low precipitation intensities (Short and Nakamura 2000). From a satellite's perspective these low intensities can be caused either by intense small-scale showers or by light large-scale precipitation, such as drizzle. Both types of precipitation might lead to similarly low precipitation rates within a PMW footprint. Most PMW footprints range between 10 and $50 \mathrm{~km}$ in resolution, which largely exceeds the size of the average rain shower of a few tens of square kilometers (Nuijens et al. 2009). Deep convection is easier to capture for satellite sensors but rather scarce in the subtropics. Therefore, precipitation monitoring is particularly challenging over the subtropical oceans. Instead of "precipitation," henceforth we refer to "light rain" as a term for a low areal precipitation rate as a satellite sensor would see it. The term light rain is appropriate because precipitation in the subtropical North Atlantic is, when averaged over the scale of a satellite footprint, 1) of low intensity (Short and Nakamura 2000) and 2) initialized by warm rain processes (Lau and $\mathrm{Wu} 2003$ ).

Light rain covers large areas in the subtropics and thus presents a challenge for current and future satellite remote sensing. The spaceborne TRMM PR and the TRMM Microwave Imager (TMI) serve as the calibrator for TMPA, called TRMM Combined Instrument (TCI). However, the TRMM PR is only sensitive to precipitation above about $0.5 \mathrm{~mm} \mathrm{~h}^{-1}$ (Kozu et al. 2001). The CloudSat Cloud Profiling Radar (CPR) is particularly sensitive to light precipitation with high spatial resolution, but the CPR swath width is limited to $1.4 \mathrm{~km}$ (Ellis et al. 2009; Mitrescu et al. 2010). Even so, CPR observations indicate that PMW sensors underestimate light rain occurrence (Stephens et al. 2012, Behrangi et al. 2012, 2014). The recently operational Global Precipitation Measurement mission aims at higher sampling as well as a higher sensitivity of PMW sensors to improve monitoring of light rain and snowfall (Hou et al. 2014).

The evaluation of current satellite climatologies requires surface-based reference data. Oceanic areas lack high-quality in situ surface-based precipitation data because gauges along coastal areas are only representative for a rather limited area, and are thus inappropriate to compare to satellite climatologies over the broader ocean. Coastal and island-based radars can obtain oceanic validation data on larger areas, although the underlying drop size distributions (DSDs) can vary substantially (Wilson et al. 2011). However, at the surface level DSDs do not differ significantly over land and ocean (Bumke and Seltmann 2012). In the western Atlantic close to the Caribbean, the Barbados Cloud Observatory (BCO) has been measuring cloud-related meteorological quantities since April 2010 (Nuijens et al. 2014). Among these data a Micro Rain Radar (MRR) measures rainfall at very high temporal resolution. Additionally, in winter 2004/05 the Rain in Cumulus over the Ocean campaign (RICO; Rauber et al. 2007) on Barbuda Island amounted to about two months of rainfall data from a horizontally scanning S-band dual-polarization Doppler radar (S-Pol). Frequent light rain events were well resolved by the S-Pol during RICO, making its data valuable for this study to compare with the satellite climatologies.

Satellite climatologies are important for climate model evaluation. Relative to satellite sensors, models overestimate the occurrence of drizzle (Stephens et al. 2010). Insufficient evaporation rates and excessive warm rain formation process in models are possible reasons for this difference (Suzuki et al. 2011; Ahlgrimm and Forbes 2014). Some GCMs face problems linked to dynamics, in which a precipitation high bias occurs in regions of subsiding air masses, and vice versa (Hirota et al. 2011). However, these findings depend on the choice of the observational reference dataset. We investigate how GPCP1DD, TMPA, and HOAPS-C represent the seasonal variability and how they perform over a subtropical oceanic area dominated by light rain. The outcome of this study may aid climate model evaluation and advance the understanding of light rain more generally.

The methodology (section 2) introduces the study area, the datasets, and the concept of analysis. The discussion (section 3) comprises three parts. Section 3a addresses the overall state and seasonal differences of light rain and its contribution to total rain over the subtropical North Atlantic. In section $3 b$ we compare the satellite datasets with ground-based radar data on a smaller scale. This part elaborates on potential differences in the light rain representation among the three satellite datasets. Section $3 \mathrm{c}$ extends the view to investigate whether the findings from 
RICO and BCO hold for larger areas and longer periods. Section 4 condenses the main findings and provides concluding remarks.

\section{Data and methods}

\section{a. Ground-based remote sensing}

The ground-based remote sensing instrumentation used in this study comprises two different radar systems: a horizontally scanning S-Pol and a vertically pointing MRR.

The S-Pol (Keeler et al. 2000), developed by the National Center for Atmospheric Research, is sensitive to measuring precipitation-sized particles with $10.68 \mathrm{~cm}$ wavelength. It was deployed on the Caribbean Sea island of Barbuda $\left(17.61^{\circ} \mathrm{N}, 61.82^{\circ} \mathrm{W}\right)$ during the RICO field campaign, operating from 24 November 2004 to 25 January 2005 (Rauber et al. 2007). In this study, surveillance scans are analyzed, which were performed at a $0.5^{\circ}$ elevation angle, covering a $150-\mathrm{km}$ domain in radius. Each scan is regridded onto a polar grid with a range resolution of $150 \mathrm{~m}$ and has undergone extensive filtering to exclude anomalous returns from ground clutter. The minimum threshold of $7 \mathrm{dBZ}$ in reflectivity is used to exclude Bragg scattering (Knight and Miller 1998). A $Z-R$ relationship is applied to convert the measured radar reflectivity $Z$ (dBZ) into a rain rate $R\left(\mathrm{~mm} \mathrm{day}^{-1}\right)$. As it strongly depends on the DSD, the selection of a particular $Z-R$ relation introduces an uncertainty (Houze et al. 2004). Here, following Nuijens et al. (2009) the $Z-R$ relation for shallow convective clouds in the TRMM PR algorithm is mainly used (Iguchi et al. 2000):

$$
Z=148 R^{1.55} \text {. }
$$

For the sake of comparison, the $Z-R$ relation derived from DSDs that were measured during RICO aircraft flights (Snodgrass et al. 2009),

$$
Z=88 R^{1.52}
$$

is also used in this study.

The vertically pointing MRR, developed by Meteorologische Messtechnik GmbH (METEK), has operated on the island of Barbados since April 2010. The MRR measures in frequency modulated continuous wave (FM-CW) mode at 24-GHz frequency (METEK 2009). Its high sensitivity combined with high temporal resolution (here 1-min averages) and a vertical resolution of 30 gates (up to 3000-m height) with 100-m vertical resolution enables detecting low-intensity small-scale rain showers. Furthermore, with the help of a comparatively large vertical scattering volume statistically reliable estimates of the
TABLE 1. Overview of utilized satellite precipitation datasets.

\begin{tabular}{lllll}
\hline & HOAPS-C & \multicolumn{1}{c}{ TMPA } & \multicolumn{1}{c}{ TMPA* } & GPCP 1DD \\
\hline Version & $\mathrm{v} 3.2$ & $\mathrm{v} 7$ & As TMPA & $\mathrm{v} 1.2$ \\
Grid size & $0.5^{\circ}$ & $0.25^{\circ}$ & $0.5^{\circ}$ & $1^{\circ}$ \\
Time step & $6 \mathrm{~h}$ & $3 \mathrm{~h}$ & $6 \mathrm{~h}$ & Daily \\
Total & $1988-2008$ & $1998-$ present & $1998-2005$ & $1996-$ present \\
period & & & & \\
\hline
\end{tabular}

DSD can be measured directly by the MRR. In an analysis of data from a scanning cloud radar Lonitz (2014) found no island effect in measurements at the $\mathrm{BCO}$, hence we assume that the measured DSD over the measurement site is representative for those that would be found over the surrounding ocean. From DSD the rain rate can be derived with higher accuracy relative to the S-Pol by integrating over the drop size $D$ :

$$
R=\frac{\pi}{6} \int_{0}^{\infty} N(D) D^{3} v(D) d D
$$

where $v(D)$ corresponds to the terminal falling velocity, $(\pi / 6) N(D) D^{3}$ corresponds to the volume of the differential droplet number density, and $D$ corresponds to the drop diameter. To derive a surface-representative rain rate only the third-lowermost layer (about $300 \mathrm{~m}$ height) of the MRR data is used (Clemens et al. 2006).

\section{b. Satellite data}

Three different publicly available satellite precipitation products are used in this study, providing rain-rate estimates at different spatial and temporal resolutions (Table 1). TMPA provides precipitation rates at 3-hourly resolution on a $0.25^{\circ}$ grid (Huffman et al. 2007), whereas HOAPS-C has 6-hourly sampling and $0.5^{\circ}$ spatial resolution (Andersson et al. 2010). By averaging we generate a coarse-grained $0.5^{\circ}$ version of TMPA (named TMPA*) with 6-hourly time step. This procedure conserves the precipitation information of TMPA by timespace averaging and enables a comparison of TMPA with HOAPS-C at equal gridbox size. From GPCP (Huffman et al. 2001) we use the current version 1.2 at 1DD resolution, which is coarser than HOAPS-C and TMPA. All three climatologies overlap during the period from 1998 to 2005.

For the overlapping period, the mainstay of HOAPS-C and TMPA are SSM/I PMW radiometers on board the polar-orbiting sun-synchronous satellites of the Defense Meteorological Satellite Program. GPCP 1DD uses SSM/I only for monthly scaling of precipitation frequency. SSM/I is a conically scanning radiometer with a channeldependent $(19,22,37$, and $85 \mathrm{GHz})$ sensor footprint of up to $12 \times 15 \mathrm{~km}^{2}$. All channels are sampled at vertical and horizontal polarization, except for the $22-\mathrm{GHz}$ channel 
(vertical). From 19 to $37 \mathrm{GHz}$ the emission signal of water droplets dominates the precipitation retrievals, whereas at $85 \mathrm{GHz}$ the scattering of ice crystals plays a major role (Levizzani et al. 2007). Kidd and Huffman (2011) provide an extensive overview on space-based instrumentation and retrieval techniques regarding precipitation estimation from passive and active microwave sensors. In the following, HOAPS-C, TMPA, and GPCP 1DD are described in more detail.

\section{1) HOAPS}

The current version 3.2 (v3.2) of HOAPS (Fennig et al. 2012) comprises essential water cycle parameters over the global ice-free ocean over more than 20 consecutive years from 1987 to 2008. An elaborate processing chain, including all available SSM/I instruments, is designed to provide a time series with dense data sampling and hence detailed information of the underlying weather situations. The precipitation retrieval uses a neural net approach and relies exclusively on SSM/I data. The neural net was trained on a global dataset of randomly selected SSM/I brightness temperatures from the year 1998. Furthermore, a careful intersensor calibration ensures a physically consistent retrieval among all SSM/I radiometers (Andersson et al. 2010). By avoiding the use of ancillary data HOAPS can be more effectively used as an independent reference for reanalysis and model evaluation (Andersson et al. 2011).

In the HOAPS retrieval procedure the ungridded HOAPS scan (HOAPS-S) orbital swath data cut off precipitation rates below $0.3 \mathrm{~mm} \mathrm{~h}^{-1}$ because below that threshold a rain signal is no longer distinguishable from background noise (Andersson et al. 2010). However, after gridding the HOAPS-S data to $0.5^{\circ} \times 0.5^{\circ} \mathrm{HOAPS}-\mathrm{C}$, precipitation rates below $0.3 \mathrm{~mm} \mathrm{~h}^{-1}$ can occur. In HOAPS-C each grid box is assigned the most recent retrieval value within the 6-h time period starting at the nominal time of $0000,0600,1200$, and 1800 UTC. If there is no overpass within that time at a certain grid box, a missing value is assigned. We exclusively use HOAPS v3.2 in this study because of its prolonged time series, enhanced temporal resolution, and improved processing of level-1 SSM/I brightness temperatures relative to its predecessor HOAPS v3 (Fennig et al. 2012).

\section{2) TMPA}

The nonglobal TMPA dataset v7 (Huffman and Bolvin 2014) was initially released in May 2012, whereas a reprocessed version was released in December 2012. In contrast to HOAPS, TMPA merges data from several satellite sensors and gauges. As the backbone, the physically based GPROF (Kummerow et al. 2011) is used to retrieve rain rates related to the vertical structure of hydrometeors and the brightness temperature measured by PMW sensors. In addition to TMI, these sensors are SSM/I, its successor SSMIS, and AMSR-E. All named PMW sensors are processed applying GPROF2010 (TMI, SSM/I), GPROF2004 (AMSR-E), or GPROF2004v (SSMIS; Vila et al. 2013). For each grid box all of the available PMW data are converted into precipitation estimates and averaged over the 3-h time range as follows: First, the TCI (or 2B31), containing PR and TMI, is averaged onto a $0.25^{\circ} \times 0.25^{\circ}$ grid. If TCI is unavailable, the PMW scanners (SSM/I, SSMIS, and AMSR-E) are averaged. If no PMW scanner is available, the PMW sounders Advanced Microwave Sounding Unit (AMSU-B) and Microwave Humidity Sounder (MHS) are employed. Geosynchronous Earth orbit (GEO)-IR satellites are used as secondary satellite information. These are calibrated against the PMW data as IR satellites have the advantage of high spatiotemporal resolution but a rather poor correlation for precipitation inferred from cloud-top temperatures (Kidd and Huffman 2011). Finally, TMPA is scaled to monthly multisatellite-gauge combination to conserve total precipitation.

\section{3) GPCP}

GPCP 1DD v1.2 (Huffman and Bolvin 2013) was released in September 2012 and, similar to TMPA, applies a combination of PMW and IR satellite data. Fractional occurrence of precipitation is retrieved from SSMIS and SSM/I satellite sensors using GPROF2004v (Vila et al. 2013) and GPROF2004 (Olson et al. 1999; Kummerow et al. 2001, 2011) and is used for monthly scaling on a $0.5^{\circ} \times$ $0.5^{\circ}$ grid. The GEO-IR satellites Geostationary Operational Environmental Satellites, the Meteorological Satellite (Meteosat), and Geosynchronous Meteorological Satellite [GMS, subsequently Multifunctional Transportation Satellite (MTSat)], are used as primary source of IR data with 3 -hourly time step at a $1^{\circ} \times 1^{\circ}$ grid. The lowEarth-orbiting (LEO)-IR NOAA satellites are accumulated to the nearest 3-hourly time on the same grid size. The coldest IR-retrieved brightness temperatures are then assigned a constant rain rate per 3-h time step according to the monthly fractional occurrence from SSM/I and SSMIS and in line with the GPCP SG monthly product. The $2.5^{\circ}$ monthly resolution is matched to the $1^{\circ}$ GEO-IR and LEO-IR GPI data (same as for TMPA). Additionally, TIROS Operational Vertical Sounder (TOVS) and Atmospheric Infrared Sounder (AIRS) are used outside of $45^{\circ} \mathrm{N}-\mathrm{S}$ and thus do not affect this study. The GPCP 1DD dataset is documented in detail by Huffman et al. (2001).

\section{c. Methods and study area}

The study area ranges from the West African coast (upstream part of average trade wind) toward the Caribbean (downstream). This large area of the subtropical 


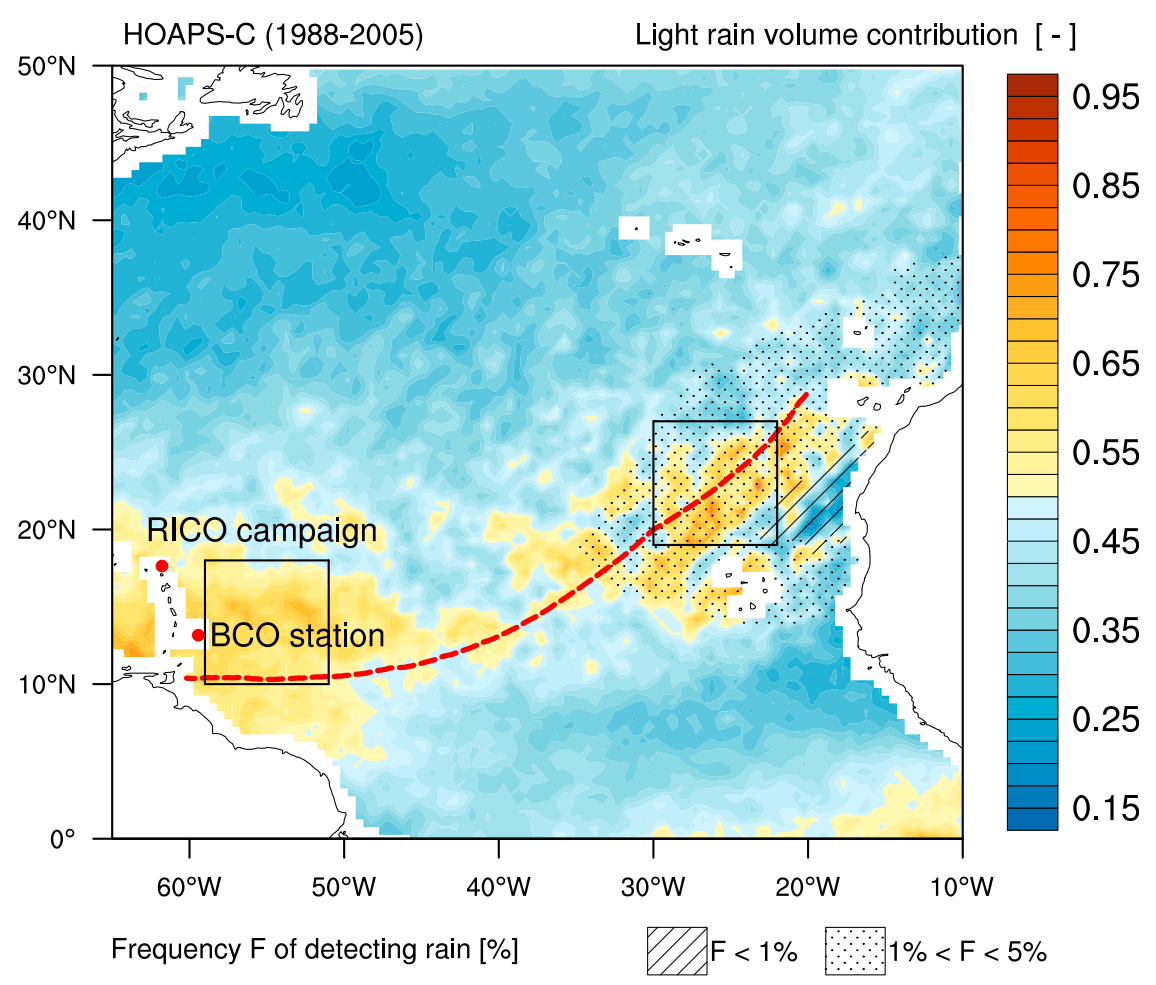

FIG. 1. Averaged light rain $\left(<24 \mathrm{~mm} \mathrm{day}^{-1}\right)$ volume contribution to total rainfall amount of HOAPS-C (1988-2005). Dotted/hatched areas refer to regions with sparse rain. The reddashed line marks the average trade wind trajectory after Sandu et al. (2010). Black squares highlight $8^{\circ} \times 8^{\circ}$ subareas upstream (east) and downstream (west), and red dots mark the locations of RICO and BCO.

North Atlantic receives most of its precipitation as light rain from shallow clouds. Here defined as rain rates less than $24 \mathrm{~mm} \mathrm{day}^{-1}$ in a $0.5^{\circ} \times 0.5^{\circ}$ box, light rain contributes $40 \%-80 \%$ to total rainfall amount according to HOAPS-C rain rates averaged over 18 years (Fig. 1). The maximum light rain contribution, partly exceeding $80 \%$, occurs along the trade wind trajectory connecting upstream and downstream regions. This trade wind trajectory (Fig. 1; red line) marks the average flow of the trade wind as deduced from Moderate Resolution Imaging Spectroradiometer (MODIS) satellite observations for May to October (2002-07) using Hybrid Single-Particle Lagrangian Integrated Trajectory model (HYSPLIT) forward and backward trajectories (Sandu et al. 2010). At the beginning (upstream) and at the end of the trajectory (downstream) we define an $8^{\circ} \times 8^{\circ}$ box (Fig. 1; black squares) to investigate rainfall conditions on a larger area on either side of the subtropical North Atlantic. These boxes and the trajectory that connects them are used to explore the seasonal variability and transformation of rainfall between the two cloud regimes, and to compare the three satellite products with each other.

The satellite climatologies require a surface reference such as radar data. For that purpose, we apply the aforementioned radar data (section 2a) from $\mathrm{BCO}$ and RICO. The BCO measures cloud-related meteorological quantities since April 2010 (Nuijens et al. 2014). Whereas the BCO is a long-term measurement, RICO was a temporary observational campaign in the Caribbean (winter 2004/05; Rauber et al. 2007) that aimed at quantifying rainfall from shallow marine cumulus clouds. Apart from these two field campaigns, other stations collect in situ atmospheric data of cloud-related quantities in the subtropical North Atlantic such as Cape Verde Atmospheric Observatory on São Vicente and, since September 2013, the Atmospheric Radiation Measurement Program site on the Azores.

\section{Results}

In the following sections, an 8-yr (1998-2005) climatology of precipitation over the subtropical North Atlantic is explored for three state-of-the-art satellite precipitation climatologies, HOAPS-C v3.2, GPCP 1DD v1.2, and TMPA v7 (Fig. 2a), focusing on a typical trade wind trajectory and two $8^{\circ} \times 8^{\circ}$ areas on either side of the North Atlantic displayed in Fig. 1. A fair comparison of precipitation from the satellite climatologies 

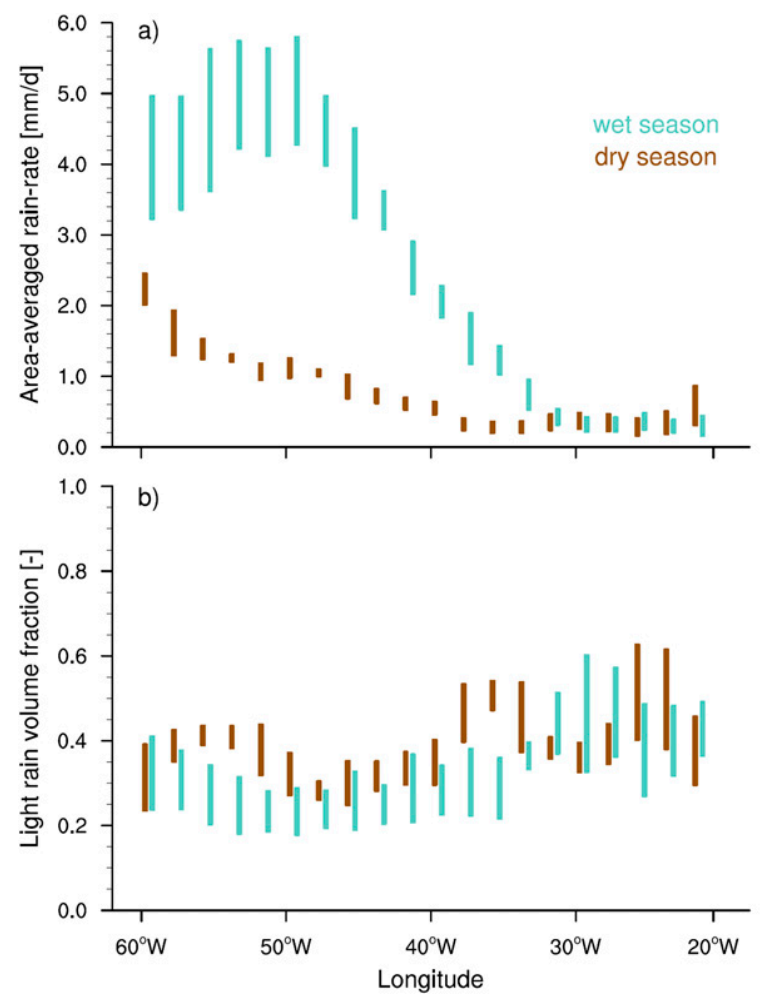

FIG. 2. The vertical bars span the range of HOAPS-C, TMPA, and GPCP 1DD (a) area-averaged $\left(2^{\circ} \times 2^{\circ}\right)$ rain rates $\left(\mathrm{mm} \mathrm{day}^{-1}\right)$ and (b) light rain $\left(<6 \mathrm{~mm} \mathrm{day}^{-1}\right)$ volume fraction along the average trade wind trajectory (Fig. 1) for dry (December-May; brown) and wet season (June-November; cyan), averaged over 8 yr (1998-2005).

requires an adjustment to equal spatiotemporal resolution, because a rain rate strongly depends on the time and space over which it is derived. If not mentioned explicitly, we always employ daily and area-averaged $\left(2^{\circ} \times 2^{\circ}\right)$ rain rates of HOAPS-C, TMPA, and GPCP 1DD. This spatiotemporal adjustment also applies to the ground-based reference data.

\section{a. Climatology of light rain over the subtropical North Atlantic from satellite climatologies}

The large-scale environment over the North Atlantic trades experiences a pronounced seasonality related to the strength of the North Atlantic subtropical high and the migration of the ITCZ (Brueck et al. 2015). During boreal winter, when large-scale vertical motion is subsiding, strong northeasterly winds prevail and high lowertropospheric stability limits convection to below the trade wind inversion. These winter months (December-May) experience half as much precipitation compared to the summer months (June-November), when subsidence and lower-tropospheric stability are reduced and deep convection from within the ITCZ and occasionally a hurricane put their mark on most of the western part of the subtropics. Henceforth, we refer to "dry season" (winter) and "wet season" (summer) to distinguish between the seasonal precipitation regimes. The seasonality is evident when comparing the 8-yr (1998-2005) area-averaged rain rates along the trade wind trajectory for the dry season (brown bars in Fig. 2) with the wet season (cyan). The vertical bars span the range of the $2^{\circ} \times 2^{\circ}$ area-averaged rain rates among HOAPS-C, GPCP $1 \mathrm{DD}$, and TMPA; that is, the top of the bar belongs to the dataset with the highest value and the bottom of the bar to that with the lowest value. Except for the eastern part of the trajectory, where precipitation is scarce and satellite differences are as large as seasonal differences, there is a clear seasonal cycle present in average rainfall. In both seasons rain rates increase downstream along the trajectory, but in the wet season rain rates peak around $50^{\circ} \mathrm{W}$ compared to $60^{\circ} \mathrm{W}$ near the Brazilian coast in the dry season (Siongco et al. 2015).

Because high rain-rate events can have a substantial influence on the average rain rate, the contribution of light rain to total rainfall amount along the trajectory is plotted in Fig. 2b. Here the light rain volume fraction is defined as the contribution of rain rates less than $6 \mathrm{~mm} \mathrm{day}^{-1}$ to total rainfall amount, where $6 \mathrm{~mm}^{\text {day }}{ }^{-1}$ is subjectively chosen. Note that this light rain threshold is markedly lower than the threshold used for HOAPS-C in Fig. $1\left(0.5^{\circ} \times 0.5^{\circ}\right)$ because the rain rates in Fig. $2 \mathrm{~b}$ refer to a 16-times-larger area of $2^{\circ} \times 2^{\circ}$. The rather conservative threshold mainly excludes heavy rain but also some intense small-scale showers from trade cumuli considered as light rain. For this study, the absolute value of the threshold plays a minor role (refer to Fig. 3a). Instead of presenting a concrete light rain fraction, we focus on changes of the light rain volume fraction with respect to season and location on the trade trajectory. The light rain volume fraction ranges between about $20 \%$ and $50 \%$ and has overall less seasonality or dependence on longitude than the area-averaged rain rate (Fig. 2b). Although, there is some indication that the light rain fractions are larger upstream close to the African coast and in the dry season. The minimum near $50^{\circ} \mathrm{W}$ likely reflects the passage of deep tropical disturbances with high rain rates.

Although the satellite products seem to agree better in their 8-yr area-averaged rain rates during the dry season (difference $<0.5 \mathrm{~mm} \mathrm{day}^{-1}$ ) compared to the wet season $\left(2 \mathrm{~mm} \mathrm{day}^{-1}\right)$, the relative differences reveal very similar values. The relative difference is defined as the ratio between the maximum value of a satellite climatology and the difference between the minimum and maximum value at a given longitude. When the relative difference is high, the range of the satellite climatologies is large related to their absolute value. Accordingly, the large spread of up to $2 \mathrm{~mm} \mathrm{day}^{-1}$ area-averaged rain 

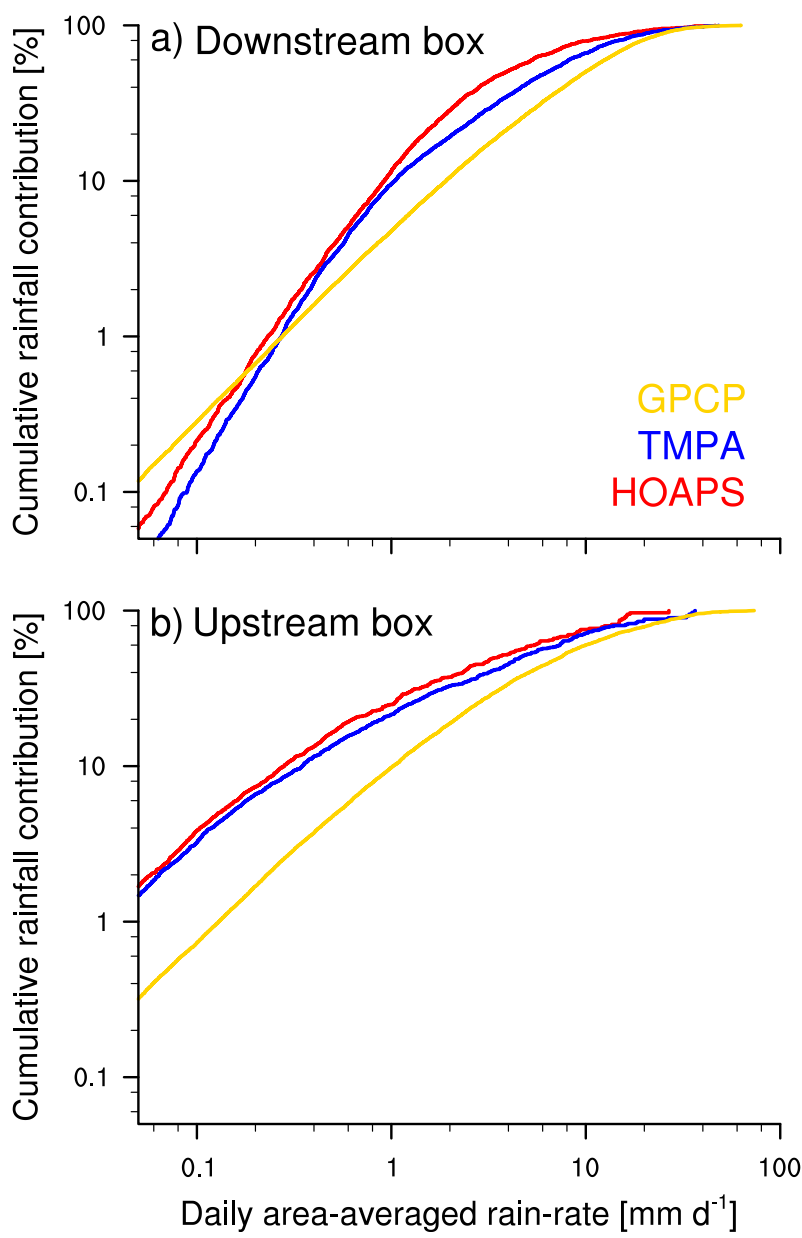

FIG. 3. Cumulative rainfall contribution in percent of daily areaaveraged $\left(2^{\circ} \times 2^{\circ}\right)$ rain rates for the 8-yr period (1998-2005) of HOAPS-C (red), GPCP 1DD (yellow), and TMPA (blue) for (a) downstream (west) and (b) upstream (east) $8^{\circ} \times 8^{\circ}$ boxes (Fig. 1).

rate in the western part during the wet season appears to be smaller $(25 \%-35 \%)$ than that for the eastern part $(45 \%-65 \%)$ when referring to relative differences. A reason for that east-west contrast is the scarcity of rainfall in the eastern part of the subtropical North Atlantic (hatched area in Fig. 1). Nevertheless, the western part is a region of higher relative differences among the satellite climatologies than the transition region around $40^{\circ} \mathrm{W}(15 \%-25 \%)$. The relative differences for the light rain volume fraction range between $10 \%$ and $40 \%$ (dry season) and $15 \%$ and $45 \%$ (wet season). At this point, quantitative differences among the satellite products stand out. The individual performance of each satellite climatology is examined in section $3 b$ whereby explanations for differences among the satellite climatologies are discussed.

The total annual rainfall amount combines rain occurrence and rain intensity by accumulating rainfall per year. We calculate the average annual rainfall amount for $8 \mathrm{yr}(1998-2005)$ over two $8^{\circ} \times 8^{\circ}$ boxes with $2^{\circ} \times 2^{\circ}$ spatial resolution on either side of the trajectory (black boxes in Fig. 1). On average, TMPA has the highest average annual rainfall amount during $8 \mathrm{yr}$ with $880 \mathrm{~mm}$, HOAPS-C $(673 \mathrm{~mm})$ and GPCP 1DD $(646 \mathrm{~mm})$ show about $25 \%$ less rainfall. The origin of these differences can be understood in more detail by an analysis of the rain intensity distribution (Fig. 3). In the downstream box, HOAPS-C, TMPA, and GPCP 1DD show similar contributions of accumulated rain rates below about $0.2 \mathrm{~mm}$ day $^{-1}$ that contribute by less than $1 \%$ to the total rain amount (Fig. 3a). However, individual rain rates below $1 \mathrm{~mm} \mathrm{day}^{-1}$ in HOAPS-C and TMPA have a stronger contribution than the same rain rates in GPCP 1DD. For instance, rain rates less than $6 \mathrm{~mm} \mathrm{day}^{-1}$ in GPCP 1DD contribute by more than $30 \%$ to the total rainfall amount, whereas for TMPA and HOAPS-C this light rain accounts for $50 \%$ and $65 \%$ of the total rainfall, respectively. Thus, in GPCP 1DD higher rain rates contribute relatively more to the average annual rainfall amount than in HOAPS-C and TMPA.

The upstream box (Fig. 3b) indicates a shift of the whole rain-rate distribution toward lower rain rates compared to the downstream box. The average annual rainfall of TMPA $(172 \mathrm{~mm})$ and GPCP 1DD $(165 \mathrm{~mm})$ reflects that reduction, whereby GPCP 1DD agrees much better with TMPA than in the downstream box. The total annual rainfall of HOAPS-C $(103 \mathrm{~mm})$ is about one-third lower. One potential reason can be that HOAPS-C observes fewer very high rain rates than TMPA and GPCP 1DD While the whole rain distribution shifts toward lower rain rates, both HOAPS-C and TMPA show a more marked increase in the contribution of rain rates less than $0.5 \mathrm{~mm} \mathrm{day}^{-1}$ compared to the downstream box, corresponding to about $15 \%$ (Fig. 3b) and 4\% (Fig. 3a) of total rainfall, respectively. In the rain-rate distribution HOAPS-C and TMPA agree relatively well, whereas GPCP 1DD differs more. GPCP 1DD confirms the higher contribution of high rain rates to total rainfall, which is even more pronounced in the previous v1.1.

Because the performance of the satellite climatologies differs between the eastern and the western part of the subtropical North Atlantic, the locally varying rain characteristics can reveal specific weaknesses of the satellite climatologies in their overall ability to detect rain. Depending on seasonality and frequency of rain, weaknesses related to sampling, sensor sensitivity, or algorithm features may be emphasized differently. Causes of different rain-rate distributions and total rainfall amounts, and the robustness of these results on shorter time periods, are investigated in the following section using ground-based radar data. The study 
focuses on the western Atlantic (downstream), where generally a broader rain-rate distribution is sampled, and where recent field measurements have provided good reference datasets.

\section{b. Comparison with ground-based radar in the downstream region}

What are typical rain intensities found in the western region of the subtropical North Atlantic where shallow cumulus clouds prevail? And which satellite product best captures such rain events? Two precipitation datasets from ground-based radars deployed on Barbuda and Barbados are used 1) to describe the character of rain in the trades and 2) as a reference for a more indepth evaluation of the performance of the three satellite products.

\section{1) INTENSITY OF RAIN FROM SHALLOW CUMULUS}

The first dataset contains two years of MRR data collected at a single location at the $\mathrm{BCO}$, which provides rain rates detected within $300 \mathrm{~m}$ above the surface at 1-min resolution (section 2a). For an average wind speed of $7 \mathrm{~m} \mathrm{~s}^{-1}$ this is equivalent to a spatial resolution of $420 \mathrm{~m}$. The second dataset contains two months of rain rates from the S-Pol radar deployed on Barbuda during RICO, which provides rain rates within an area of $150 \mathrm{~km}$ in radius on a grid mesh of $150 \mathrm{~m}$ in range and $0.67^{\circ}$ in azimuth, about every $20 \mathrm{~min}$.

The normalized frequency distributions of these instantaneous rain rates (i.e., no further averaging over time or space is performed) from the MRR and S-Pol highlight the prevalence of rain with low intensities (Fig. 4). Rain rates less than $8 \mathrm{~mm}$ day $^{-1}$ have a frequency of occurrence of $10 \%$ or more. On the other hand, intensities of $25 \mathrm{~mm} \mathrm{day}^{-1}$, which are typically significant rain showers, are not scarce and reinforce the earlier statement that rain from shallow clouds is not necessarily light rain.

The TRMM $Z-R$ relation [Eq. (1)], developed for shallow convection, agrees better with the MRR at lower rain rates, whereas the RICO $Z-R$ relation [Eq. (2)] agrees better with the MRR at higher rain rates. This uncertainty, related to the conversion of the measured radar reflectivity into a rain rate, can lead to differences in estimated rain rates of $30 \%-50 \%$ (Nuijens et al. 2009). The MRR overall has a higher frequency of detecting very high rain rates $\left(>50 \mathrm{~mm} \mathrm{day}^{-1}\right)$, which may be because the MRR measures during both the dry and the wet season, whereas the S-Pol only measured for about two months in total during the dry season. Although the S-Pol also measured some rain from deeper mixed-phase clouds during RICO [section 3b(2)], shallow clouds and light rain dominate during these months (Fig. 2). Because of its decreasing pixel resolution with increasing distance away from the S-Pol radar, the S-Pol rain signal reduces by about $2 \mathrm{dBZ}(100 \mathrm{~km})^{-1}$ (Fig. 3.2 in Nuijens 2005). This, and the fact that the center of the radar beam at large distances is located at increasing heights, within and near the tops of clouds, may be a reason for an underestimation of rain rates by S-Pol compared to the MRR.

Although the downstream western Atlantic region receives about twice as much rain during the wet season compared to the dry season, the rain occurrence remains almost constant at about $5.5 \%$, according to the MRR at $\mathrm{BCO}$. This prevalence of frequently occurring low rain intensities in the downstream region during the dry season provides a well-suited framework to evaluate satellite data. For this evaluation only the two months of S-Pol data are used, because this period overlaps with the available period of HOAPS-C, TMPA, and GPCP 1DD. Additionally, the S-Pol data provide a spatial image of rain rates to which the satellite climatologies can be mapped. The comparison with the BCO data also demonstrates that its statistics are representative of the broader region and longer time periods.

\section{2) THE SATELLITES' VIEW OF RAIN DURING RICO}

During most of the RICO period the conditions were typical for shallow convection with cloud tops below the freezing level; however, a few exceptional days were observed, where deep convective disturbances passed the region (13-14 December, 9-10 January, and 13 January). A time series of S-Pol area-averaged rain rates over the northeast (NE) S-Pol radar domain (Fig. 5) shows that those days experienced more intense rainfall with rain rates exceeding $10 \mathrm{~mm} \mathrm{day}^{-1}$. Note that the calculation of area-averaged rain rates includes both raining and nonraining grid boxes. Hence, areaaveraged rain rates are much smaller than the pixel rain rates at original resolution (Fig. 4), and are most often below the $6 \mathrm{~mm}$ day $^{-1}$ threshold used in Fig. $2 \mathrm{~b}$ to define the light rain volume fraction.

For a comparison with the satellite products, rain rates from S-Pol are averaged to daily area-averaged rain rates for the two-month RICO period. For the spatial average we use only the NE S-Pol radar domain in order to avoid any island effects. This limitation is necessary because the HOAPS dataset masks data within $50 \mathrm{~km}$ distance to any coast to avoid land influences on the measured brightness temperatures. The NE S-Pol radar domain also comprises an area of approximately $2^{\circ} \times 2^{\circ}$, overlapping with 4,16 , and 64 grid boxes at original resolution of the satellite data (Fig. 6). During the 58 full days of RICO the S-Pol measured rain on all but one day (see RR $>0 \mathrm{~mm}$ day $^{-1}$ in Fig. 7). Clearly all of the three satellite climatologies miss rain on a number of days. 


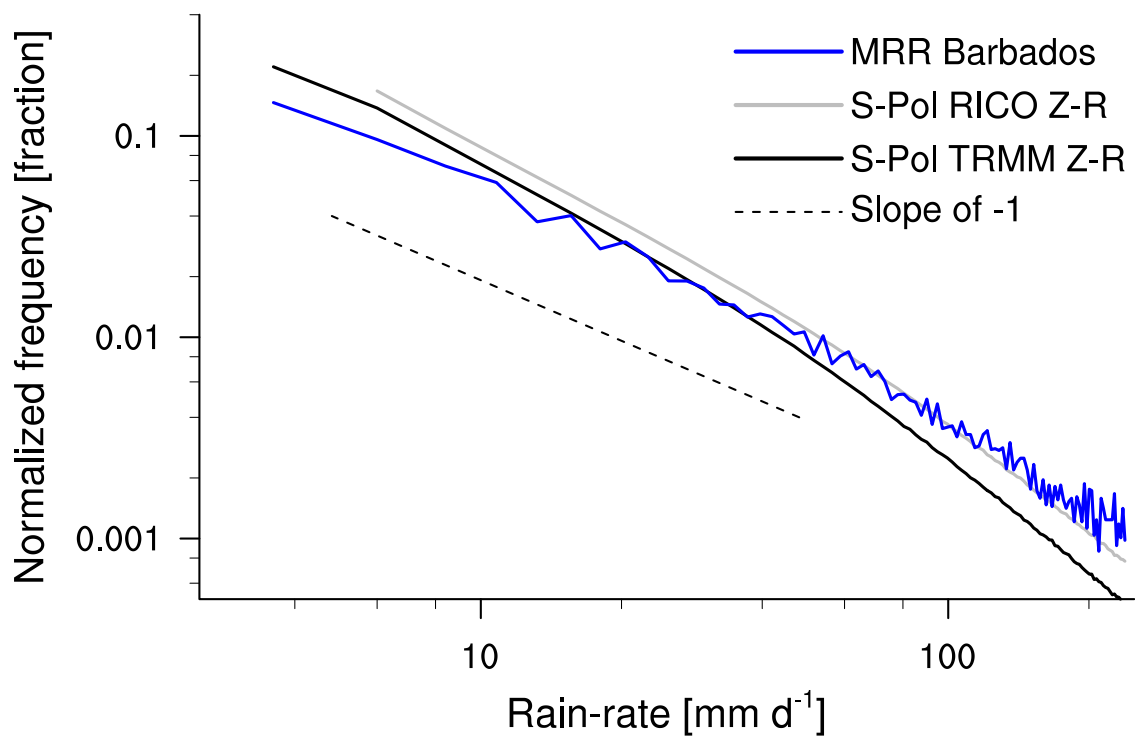

FIG. 4. Frequency of occurrence of rain rates from MRR (April 2010-April 2012) deployed at BCO (blue) and the S-Pol during RICO [black: $Z-R$ Eq. (1); gray: $Z-R$ Eq. (2)]. Rain rates < $2.64 \mathrm{~mm}$ day $^{-1}$ are not shown because of the $7-\mathrm{dB} Z$ minimum threshold applied to S-Pol. The dashed line marks the slope where all rain rates contribute equally to rainfall.

However, the number varies substantially with GPCP 1DD observing rain on only 25 days, whereas HOAPS-C (38) and TMPA (53) perform better. The choice of the $Z-R$ relation matters for the classification into days with, on average, light to moderate rain $\left(0-1 \mathrm{~mm} \mathrm{day}^{-1}\right)$ from days with on average intense rain $\left(>1 \mathrm{~mm} \mathrm{day}^{-1}\right)$. As seen in Fig. 4, the TRMM $Z-R$ relation leads to lower rain rates than the RICO $Z-R$ relation. Regardless of the $Z-R$ relation, days with, on average, less intense rain are mostly responsible for the observed differences in rain occurrence among the satellite climatologies.

If days are very heterogeneous in their temporal distribution of rain events-for instance, if the early morning was rainy, whereas the remainder of the day was dry-the limited satellite overpasses may become an issue, especially when only a short period is considered such as here. For HOAPS-C the chance of detecting a rain event is completely bound to available overpasses of SSM/I, whereas GPCP 1DD and TMPA use additional data sources to fill gaps of missing SSM/I overpasses. During the whole RICO period, one day (21 January) contained no SSM/I overpass at all, and five days had only one overpass. In those cases with fewer than three SSM/I overpasses per day, HOAPS detected less rain than the other products (not shown). The fact that HOAPS has fewer days with rain than TMPA (Fig. 7) turns out to be related to a limited overpass sample, although differences in their detection algorithm also play an important role, a point we come back to later. The poorer performance of GPCP 1DD over the NE S-Pol domain jumps out. GPCP
1DD tends to observe rain on days with disturbed conditions but frequently misses light rain. Even though both GPCP 1DD and HOAPS-C contain SSM/I sensor data, their retrievals are fundamentally different. HOAPS-C only uses available SSM/I overpasses to retrieve the spatial rain distribution and rain intensity per 6-hourly time step, whereas GPCP 1DD calculates the fractional occurrence on a monthly basis from SSM/I and SSMIS using GPROF2004. This percentage of time steps with rain is then distributed among the coldest IR-retrieved 3-hourly time steps, assigning a constant rain rate, which sums up to the GPCP SG monthly product. Thus, the low rain occurrence in GPCP 1DD largely depends on the distribution of the coldest IR-retrieved brightness temperatures, which are mainly caused by clusters of deeper convective clouds and possibly surrounding cirrus.

The satellite products estimate daily area-averaged rain rates that are, on average, somewhat higher than what is measured by the S-Pol radar (Fig. 8). HOAPS-C and TMPA match the cumulative rain contribution of the $\mathrm{S}$-Pol radar up to intensities of about $0.5 \mathrm{~mm} \mathrm{day}^{-1}$. Between 0.4 and $4 \mathrm{~mm} \mathrm{day}^{-1}$, GPCP 1DD strongly underestimates the contribution of these rain intensities to the total rain amount; TMPA has a similar tendency. However, HOAPS-C agrees well with the rain-rate distribution of the RICO $Z-R$ relation of S-Pol, whereas the TRMM $Z-R$ distribution contains a higher fraction of low rain rates. GPCP $1 D D$ overestimates the daily areaaveraged rain rates the most, with up to one order of magnitude higher daily area-averaged rain rates than the 


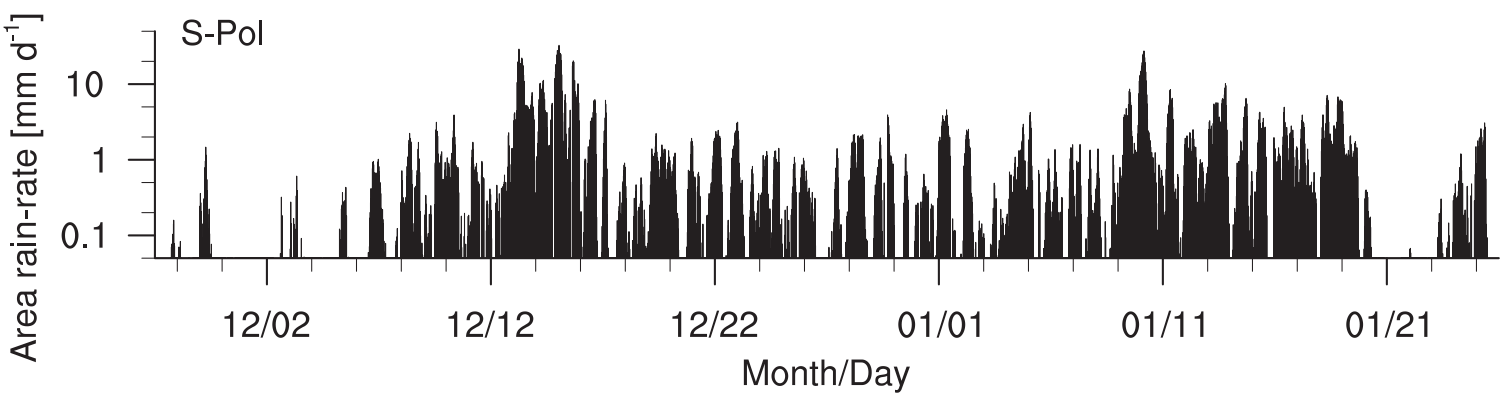

FIG. 5. Time series of area-averaged (NE S-Pol radar domain) rain rates (mm day ${ }^{-1}$ ) using the TRMM $Z-R$ relation [Eq. (1)] for the RICO period.

S-Pol radar. The S-Pol radar yet might underestimate the rain rates because of its decreasing resolution with range, as mentioned in section $3 \mathrm{~b}(1)$. The differences between satellite and radar data at higher rain rates may be somewhat more pronounced because of the relatively small sample size where single intense rain events can have a strong influence. But overall the structure of the cumulative distribution resembles the data for the 8 -yr period in the downstream region (Fig. 3a). Thus, in the cumulative rain contribution, GPCP 1DD in particular overestimates the daily area-averaged rain rate as compared with the S-Pol radar.

The daily area-averaged rain rate is a function of the fractional area covered by rain (rain-covered area) multiplied by the average rain rate of all raining grid boxes (conditional rain rate). The rain-covered area depends on the difference between the considered gridbox size of the dataset and the chosen domain size, and the rain detection. The RICO domain size is the NE S-Pol radar domain $\left(2^{\circ} \times 2^{\circ}\right)$. For a detected small rain shower, the rain-covered area mainly depends on the dataset gridbox size, which determines the minimum rain-covered area. In GPCP 1DD the minimum rain-covered area is $25 \%$ of the domain size (Fig. 6), whereas TMPA has a minimum area fraction of less than $2 \%$ ( 1 out of 64 grid boxes). In contrast to the arbitrarily chosen gridbox and domain size, the rain detection strongly depends on the retrieval algorithm of the satellite climatologies. The average raincovered area at original spatial resolution amounts to $3 \%$ for the S-Pol radar, $31 \%$ for HOAPS-C, $30 \%$ for GPCP $1 \mathrm{DD}$, and $58 \%$ for TMPA. These estimates reveal two distinct underlying causes: 1 ) The satellite datasets provide markedly higher average rain-covered area fractions than the S-Pol, which is related to their larger dataset gridbox size and lower sampling frequency before averaging relative to S-Pol. This effect dominates the average rain-covered area of the S-Pol radar because the resolution differences before and after averaging are much higher than for the satellite datasets. 2) The rain occurrence mainly influences the average rain-covered area among the satellite datasets, explaining the highest area fraction but lowest gridbox size of TMPA in comparison with HOAPS-C and GPCP 1DD according to Fig. 7. The average rain-covered area depends on retrieval-specific features such as rain detection, and the difference of the spatiotemporal resolution chosen for reaggregation. The satellite climatologies' average rain-covered area is a stronger function of effects on the retrieval level because of their similar spatiotemporal dataset resolution in comparison with the chosen aggregation scale, whereas the S-Pol rain-covered area stronger scales with resolution differences through averaging.

The distinct effect of resolution versus rain detection among the datasets is displayed in Fig. 9, which demonstrates the partitioning between rain-covered area and conditional rain rate, whereas all datasets were averaged to daily rain rates over the $2^{\circ} \times 2^{\circ} \mathrm{NE} \mathrm{S-Pol} \mathrm{radar} \mathrm{do-}$ main. The area-averaged rain rate by the S-Pol is a much stronger function of the rain-covered area than of the conditional rain rate, a point noted by Nuijens et al. (2009) in accordance with much earlier findings (Doneaud et al. 1984). Although clouds with different dimensions produce different rain intensities-for instance, deeper clouds with a larger area coverage may rain more heavily - often a wide range of rain rates is sampled, and even isolated small-sized cumuli can produce high-intensity, albeit localized, rain showers. Because of this, the area-averaged rain rate strongly depends on the actual coverage of rain. However, for the satellite products the daily area-averaged rain rate depends more strongly on the conditional rain rate than on the rain-covered area. The fact that rain showers are usually smaller than the satellite grid boxes causes a stronger tendency to saturate the whole area (i.e., $100 \%$ rain cover), which decreases the influence of the raincovered area compared to the conditional rain rate, and narrows the rain intensity distribution (Field and Shutts 2009). Consistent with that, the conditional rain rate of the satellite climatologies is much lower than that of the S-Pol. Whereas the S-Pol radar scales with area, the 


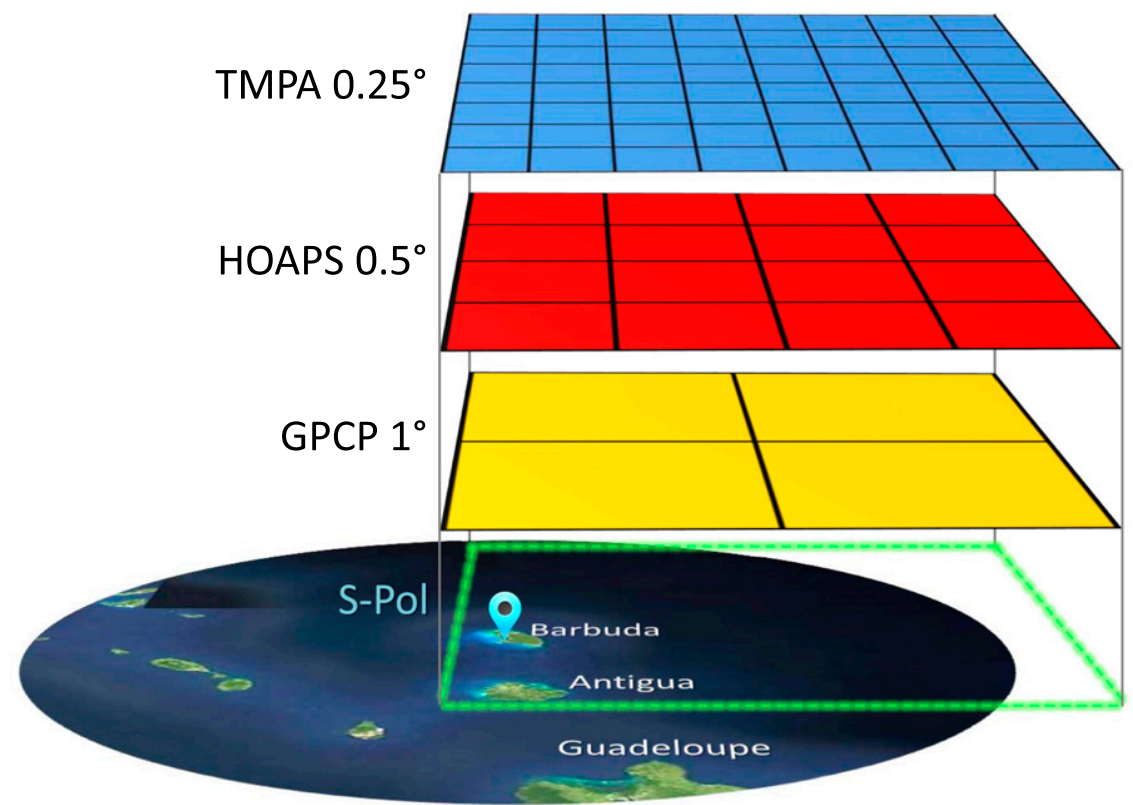

FIG. 6. Schematic overview of satellite gridbox sizes (TMPA $0.25^{\circ}$ : blue; HOAPS-C $0.5^{\circ}$ : red; GPCP 1DD $1^{\circ}$ : yellow) and S-Pol radar domain with the S-Pol centered on Barbuda (blue marker).

satellite climatologies tend to scale with rain intensity. Combined, the overestimation of the rain-covered area by the satellite datasets outweighs the underestimation in the conditional rain rate, which leads, on average, to larger daily area-averaged rain rates for the satellite products relative to the S-Pol radar, as seen in Fig. 8.

This net effect can give a misleading picture of the satellite climatology performance. Datasets like GPCP 1DD that partly fail to detect light rain on days characterized by shallow convection may still provide higher area-averaged rain rates than climatologies with a higher sensitivity for light rain by overestimating the rain intensity on other days. On average, both types of satellite climatologies might obtain comparable light rain volume fractions (Fig. 2).

\section{3) HOAPS-C VERSUS TMPA}

Although HOAPS-C and TMPA both perform well in their contribution of light rain to total rain during the RICO period, there are differences. For instance, HOAPS-C estimates lower area-averaged rain rates than TMPA (Fig. 8), because it has, on average, a smaller area covered by rain. The lower rain occurrence during RICO (Fig. 7) hints that HOAPS-C has a smaller capability to detect rain compared to TMPA. To elaborate more on the performance of TMPA and HOAPS-C, we conduct a direct comparison at a resolution that includes only those time steps in which both satellite products provide nonmissing data. For HOAPS-C $66 \%$ of the potential 6-hourly time steps remain during RICO (vs 100\% for TMPA). We regrid TMPA from its native grid $\left(0.25^{\circ}\right)$ onto a $0.5^{\circ}$ grid by area averaging every four grid boxes that overlap with one HOAPS-C grid box. The 3-hourly time step of TMPA is reduced to match HOAPS-C by averaging every two time steps. This coarse-grained version TMPA* ensures that an equal number of grid boxes can be considered in the analysis while the rain amount is conserved.

The overall number of grid boxes with rain differs significantly during RICO, with TMPA* (37\%) detecting rain more than twice as often as HOAPS-C (15\%; Table 2). HOAPS-C and TMPA* agree in $71 \%$ of the grid boxes that it either rains $(13 \%)$ or does not rain (58\%), which leaves $29 \%$ of cases where they disagree. Most of the time this is because HOAPS-C does not show rain when TMPA* does $(27 \%)$, and only $2 \%$ vice versa. In this respect, the recent version TMPA v7 led to major improvements relative to the previous v6, which performed more similarly to HOAPS-C. For instance, the rain fraction increased from $22 \%$ to $37 \%$ and the number of cases where TMPA sees rain and HOAPS-C does not almost doubled. This improvement of TMPA is mainly related to the improved sounder algorithm of AMSU input estimates (Huffman and Bolvin 2014). For the reason that TMPA agrees best with the S-Pol rain occurrences during RICO (Fig. 7), we think the detections in TMPA are real. 


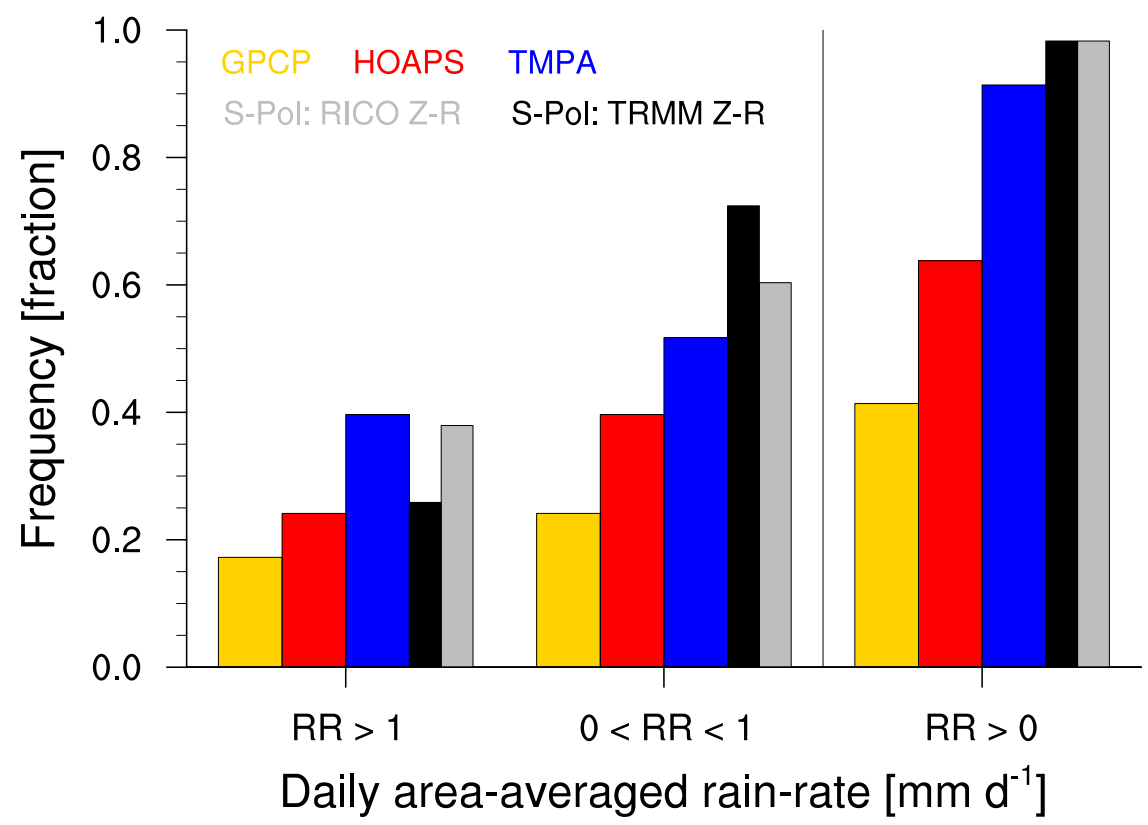

FIG. 7. Histogram of relative fraction of 58 RICO days with light $\left(0-1 \mathrm{~mm} \mathrm{day}^{-1}\right)$ and moderate to intense $\left(>1 \mathrm{~mm} \mathrm{day}^{-1}\right.$ ) daily area-averaged rain rates of HOAPS-C (red), TMPA (blue), GPCP 1DD (yellow), and S-Pol shown as thin bars for the TRMM $Z-R$ [Eq. (1), black] and RICO $Z-R$ [Eq. (2), gray] over the NE S-Pol radar domain.

The disagreement between TMPA* and HOAPS-C may be sought in various explanations. The additional sampling of microwave sensor data in TMPA, such as TMI, AMSU, AMSR-E, or MHS data, can fill gaps of missing SSM/I overpasses in HOAPS-C but cannot explain the better performance of TMPA* at nonmissing time steps of HOAPS-C. However, the time averaging applied in TMPA* might increase the rain occurrence in TMPA* if a marked time difference is present between the SSM/I overpass used in HOAPS-C and the additional PMW overpass used in TMPA. A large time difference can be related to the incomplete overlapping periods ( 4.5 of $6 \mathrm{~h}$ ) between HOAPS-C and TMPA*, whereas the remaining cases are likely related to differences in the retrieval algorithms. In particular the rain/no-rain distinction strongly depends on model assumptions and observed input parameters, which must be subjectively chosen (Stephens and Kummerow 2007).

Using the ungridded HOAPS-S (scan) data at original SSM/I scan resolution, the performance of HOAPS-C during RICO is explored in more detail by matching each HOAPS-S scene to the corresponding S-Pol radar scan (not shown). Because of the 20-min resolution of the S-Pol radar, the HOAPS-S images can be matched in time quite closely ( $<10 \mathrm{~min}$ time lag). For TMPA this comparison is not performed because of the various satellite sources entering the product. We find that HOAPS-S never falsely indicates rain compared to S-Pol (false alarm). As such, the $2 \%$ of cases in which HOAPS-C shows rain and TMPA does not must therefore be related to the different algorithms used. In addition, the HOAPS-S study reveals that for S-Pol scenes in which rain covers more than $2 \%$ of the NE radar domain, HOAPS-S always depicts rain. In contrast, HOAPS-S detects rain at rain-covered areas of less than $2 \%$ only when somewhat larger clusters are heterogeneously

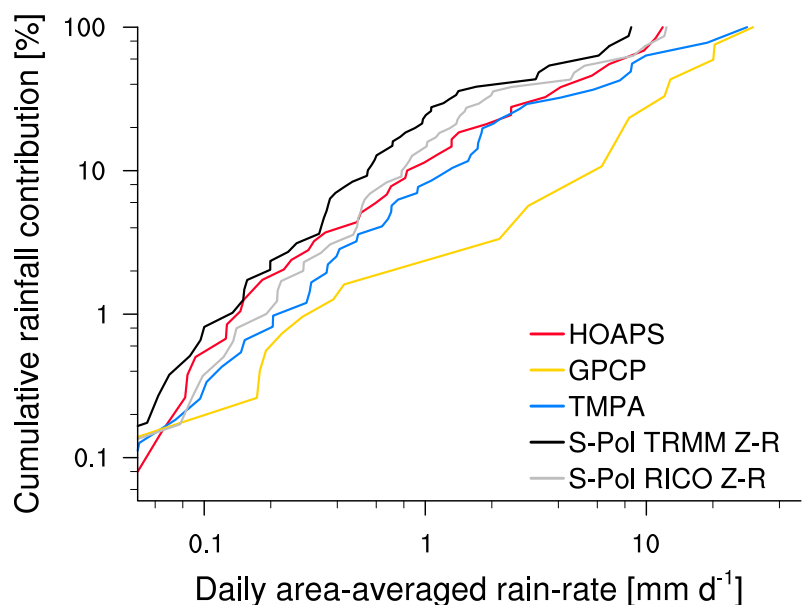

FIG. 8. Cumulative view on sorted daily area-averaged rain rates for NE S-Pol radar domain during RICO with HOAPS-C (red), TMPA (blue), GPCP 1DD (yellow), and S-Pol [black: TRMM $Z$ $R$, Eq. (1); gray: RICO $Z-R$, Eq. (2)]. 

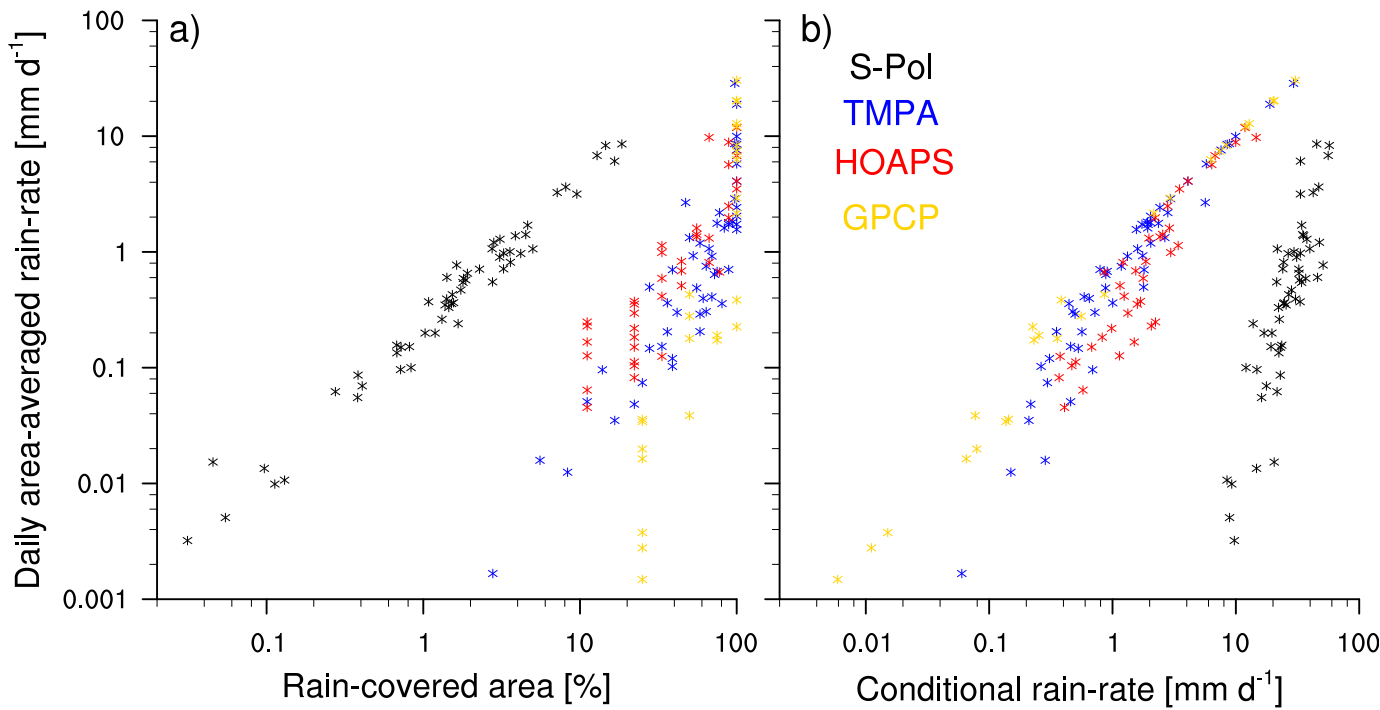

FIG. 9. Daily area-averaged rain rate $\left(\mathrm{mm} \mathrm{day}^{-1}\right)$ of TMPA, HOAPS-C, GPCP $1 D D$, and S-Pol vs (a) rain-covered area $(\%)$ and (b) conditional rain rate (only rainy grid boxes; $\mathrm{mm} \mathrm{day}^{-1}$ ) over the NE S-Pol radar domain.

distributed. If isolated rain showers are small and homogeneously distributed, covering less than $1 \%$ of the radar area, HOAPS-S is unable to detect the rain echo. In these situations of very small, homogeneously distributed showers or scenes of unavailable SSM/I overpasses, TMPA typically outperforms HOAPS-C.

\section{c. Rain intensity and occurrence in the subtropical North Atlantic upstream and downstream region}

The comparison of the three satellite climatologies with ground-based radar observations during the two-month RICO campaign in the downstream region emphasizes the relatively poor performance of GPCP 1DD in regions where rainfall is produced by isolated smaller cumuli (Fig. 7). In turn, HOAPS-C and especially TMPA demonstrate a better ability to detect rain on days when low rain intensities dominate (daily area-averaged rain rates $<$ $1 \mathrm{~mm} \mathrm{day}^{-1}$ ). Hence, in their contribution to total rainfall (Fig. 8), rain rates less than $1 \mathrm{~mm} \mathrm{day}^{-1}$ are not negligible, albeit still underestimated. In GPCP 1DD such rain rates have hardly any contribution to total rain amount.

The rain intensity distribution during RICO (Fig. 8) is similar to the 8 -yr average in the downstream region (Fig. 3a). This suggests that the differences in conditional rain rates and rain-covered area between the satellite climatologies during RICO are representative for the region and make their imprint on the climatology. A frequency distribution (Fig. 10) compares the rain-rate distributions of HOAPS-C and TMPA* at $0.5^{\circ}$ resolution [as used in section $3 \mathrm{~b}(3)$ ] for the same downstream (west) and upstream (east) $8^{\circ} \times 8^{\circ}$ boxes for the 8 -yr period 1998-2005. Note that Fig. 10 cannot be compared directly to Fig. 4 because S-Pol radar and MRR have a much higher spatial resolution than the satellite climatologies. The results from the shorter RICO period and smaller radar domain are confirmed for the 8-yr period along the trajectory (Fig. 10). TMPA* v7 (blue) produces higher rain rates above $12 \mathrm{~mm} \mathrm{day}^{-1}$ than HOAPS-C in both regions over the subtropical North Atlantic, whereas HOAPS-C provides more rain rates between 4 and $12 \mathrm{~mm} \mathrm{day}^{-1}$. Similar to Figs. 3 and 8, HOAPS-C and TMPA are alike at very low rain rates. However, along the whole trajectory TMPA* has a higher overall frequency to detect rain than HOAPS-C (Fig. 11), reaching more than $40 \%$ in the western part of the subtropical North Atlantic (HOAPS-C: 25\%). The higher rain occurrence of TMPA is of similar order, as shown in Fig. 7, and confirms the vast improvement from TMPA* v6 to v7 that is mainly due to improvements with AMSU data.

The overall rain occurrence of the MRR during two years of measurement at 1 -min resolution is $5.5 \%$ [section $3 \mathrm{~b}(1)]$. To better represent the temporal sampling of the satellite datasets, we average all 1-min rain rates within a 6-h period. This time averaging drastically increases the MRR rain occurrence toward $55 \%$. This difference indicates that TMPA might still slightly underestimate the rain occurrence, which agrees with findings of Behrangi et al. (2014), who combined the CloudSat CPR with the TRMM PR to be sensitive to both low and high precipitation intensities. Nevertheless, the values of MRR and TMPA cannot be compared directly because of different time periods and slightly different locations. The MRR rain occurrence also reveals that the time step strongly influences the rain occurrence. In other words, a rain rate always needs to be considered with respect to its underlying 
TABLE 2. Nonmissing data ( $\%$; top half of table) and contingency table (\%; bottom half of table) for rain rates $R$ of TMPA* v7 (values for v6 in parentheses) and HOAPS-C at $0.5^{\circ}$ for 58 days of RICO (NE radar domain).

\begin{tabular}{lcc}
\hline \hline & HOAPS-C & TMPA*v7 (v6) \\
\hline Pixels without rain & 85 & $63(78)$ \\
Pixels with rain & 15 & $37(22)$ \\
& TMPA* v7 (v6) & TMPA* v7 (v6) \\
& $R>0$ & $R=0$ \\
\hline HOAPS-C $R>0$ & $13(9)$ & $2(6)$ \\
HOAPS-C $R=0$ & $27(14)$ & $58(71)$ \\
\hline
\end{tabular}

area and time step, which are limited by the satellite sensor footprint and sampling rate, respectively.

The statistics for the entire subtropical North Atlantic region $\left(10^{\circ}-30^{\circ} \mathrm{N}, 20^{\circ}-60^{\circ} \mathrm{W}\right)$ are given in Table 3 , whereby the values in parentheses correspond to the $8^{\circ} \times 8^{\circ}$ downstream (west) and upstream (east) boxes as displayed in Fig. 1. As during RICO, TMPA* v7 detects rain more often (26\%) than HOAPS-C (10\%). In $21 \%$ of the cases TMPA* v7 disagrees with HOAPS-C, whereas the ratio of disagreement to agreement is larger in the western region $(27 \% / 73 \%)$ than in the eastern region $(11 \% / 89 \%)$. From these longitudinal differences we infer that, besides rain occurrence and rain intensity, the rainfall patterns are important for the detection, whereby more widespread raining areas are more easily distinguishable from widespread nonraining areas. As suggested before, the main reasons for the better performance of TMPA relative to HOAPS-C are algorithm related; additional sampling of PMW sensors used in TMPA is an advantage.

\section{Summary and conclusions}

Three different satellite climatologies are compared and evaluated against ground-based remote sensing radar data to estimate rain occurrence and intensity over the subtropical North Atlantic. In this oceanic area shallow clouds with tops below the freezing level dominate, frequently raining at both low and high rain intensities, as observed by the pointwise vertically scanning MRR deployed at BCO on Barbados as well as a S-Pol radar installed on Barbuda for surveillance scans during the RICO campaign. The large footprint size of most PMW satellite sensors can lead to an ambiguity of small-scale intense rain showers and widespread low-intensity rainfall. Although these clouds can rain at higher intensities, we refer to their rainfall as light rain, because intense but isolated showers covering a small area will lead to relatively low area-averaged rain rates, compared to deeper and more widespread convection when observed by

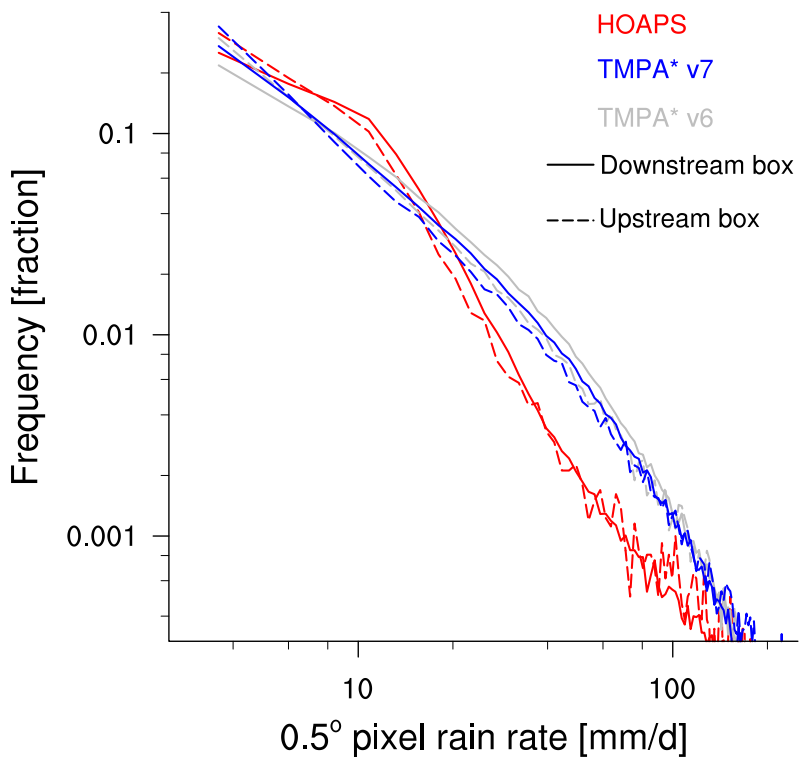

FIG. 10. The frequency distribution of rain rates $\left(\mathrm{mm} \mathrm{day}^{-1}\right)$ at $0.5^{\circ}$ for the eastern upstream box (solid line) and the western downstream box (dashed line) for HOAPS-C (red), TMPA* current v7 (blue), and the previous v6 (gray).

satellite sensors over larger areas. For our comparison, we average all datasets to daily area-averaged $\left(2^{\circ} \times 2^{\circ}\right)$ rain rates, which is a representative measure for the rain amount in a certain area within one day.

During the dry season (December-May), low rain intensities dominate in the downstream western Atlantic region of the trades with a higher fraction of light rain contributing to total rainfall amount. This region receives twice as much rainfall during the wet season (JuneNovember) compared to the dry season caused by additional convective rain of higher intensities in connection with a lower volume fraction of light rain. Toward the upstream eastern Atlantic region, these seasonal differences vanish and rainfall is scarce. For these reasons, the downstream region during the dry season is well suited to evaluate the ability of three satellite climatologies to capture light rain events.

We compare 58 full days of S-Pol radar data from the RICO campaign (winter 2004/05) with three satellite climatologies. The satellite datasets HOAPS-C, TMPA, and GPCP 1DD underestimate the rain occurrence as compared to the S-Pol radar; TMPA misses $7 \%$ of the rainy days during RICO, whereas HOAPS-C misses $33 \%$ and GPCP $1 D D$ misses $56 \%$. The deficit of GPCP 1DD is likely caused by insufficient sensitivity for light rain of the GPROF2004 algorithm using SSM/I and SSMIS, whereas the partitioning driven by IR satellite sensors is rather inaccurate. HOAPS-C has missing data in one-third of its 6-hourly time steps during RICO because of missing SSM/I overpasses. TMPA profits from 


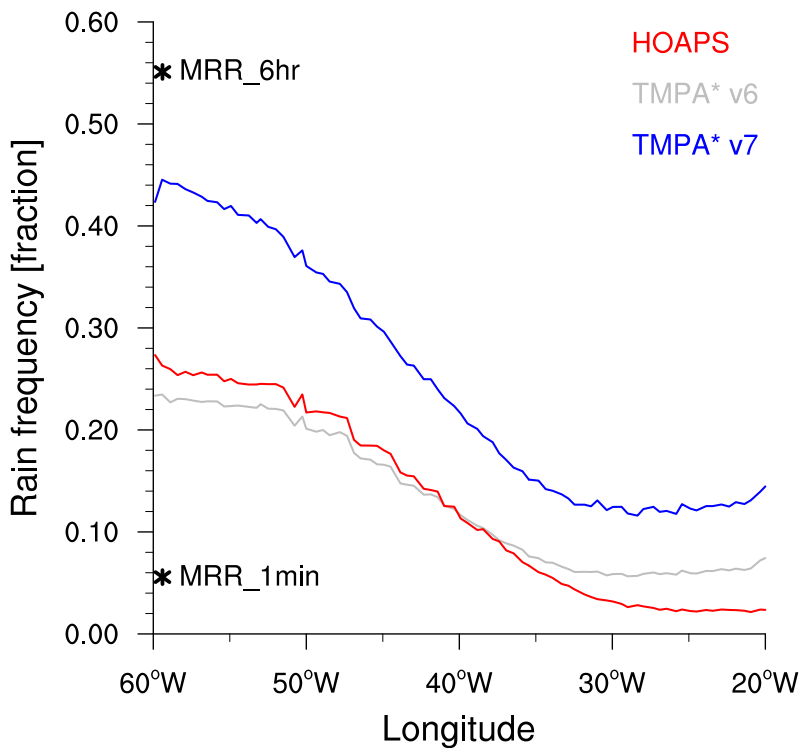

FIG. 11. The rain occurrence (fraction of time steps with observed rain) along the entire trade wind trajectory. The asterisks indicate the rain occurrence observed by the MRR located on Barbados for 1-min (MRR_1min) and 6-h averaged time step (MRR_6hr).

its calibrator TCI in combination with the more recent GPROF2010 as well as PMW sounders, which improve the performance against HOAPS-C and GPCP 1DD. We further compare the satellite climatologies for 8 years over a larger area in the subtropical North Atlantic, giving similar results. The combination of a markedly higher rain occurrence and high average rain intensity at $0.5^{\circ}$ in TMPA relative to HOAPS-C and GPCP 1DD causes higher daily area-averaged rain rates and total rain amounts in TMPA for most parts of the subtropical North Atlantic.

In the satellite climatologies the average rain intensity from all rainy grid boxes at original resolution (conditional rain rate) contributes stronger to the daily area-averaged rain rate than the rain-covered area. Coarse spatial resolution, and in particular the temporal averaging of satellite rain rates, diminishes that relationship and narrows the rain intensity distribution (Field and Shutts 2009; Liu and Allan 2012). Although the dataset spatiotemporal resolution has no influence on the actual ability of a satellite climatology to detect rain, it influences the partitioning between conditional rain rate and rain-covered area. The S-Pol radar scales much more strongly with the raincovered area than with the average rain intensity measured. The relationship between rain-covered area and average rain intensity should thus depend on the spatial resolution of the dataset. This is not apparent in the satellite datasets, given that their rain-covered area more strongly depends on rain detection than resolution
TABLE 3. Nonmissing data ( $\%$; top half of table) and contingency table (\%; bottom half of table) for rain rates $R$ of TMPA* 77 and HOAPS-C at $0.5^{\circ}$ for the subtropical North Atlantic (from $10^{\circ}$ to $30^{\circ} \mathrm{N}$ and from $20^{\circ}$ to $60^{\circ} \mathrm{W}$; numbers to left of parentheses) and the $8^{\circ} \times 8^{\circ}$ west (downstream; first numbers in parentheses) and east (upstream; second numbers in parentheses) boxes on either side of the subtropical North Atlantic for 1998-2005 and considering the average trade wind trajectory, as described in Fig. 1 and the text.

\begin{tabular}{lcc}
\hline \hline & HOAPS-C & TMPA* \\
\hline Nonraining cases & $90(81 / 97)$ & $74(61 / 87)$ \\
Raining cases & $10(19 / 3)$ & $26(39 / 13)$ \\
& TMPA* $R>0$ & TMPA* $R=0$ \\
\hline HOAPS-C $R>0$ & $9(16 / 2)$ & $2(3 / 0)$ \\
HOAPS-C $R=0$ & $19(24 / 11)$ & $71(57 / 87)$ \\
\hline
\end{tabular}

differences. The HOAPS scan data (HOAPS-S) revealed that HOAPS-C certainly detects rain showers covering at least $2 \%$ of the NE S-Pol radar domain during RICO if an $\mathrm{SSM} / \mathrm{I}$ overpass is available. A coarse-grained $0.5^{\circ}$, 6-hourly averaged version of TMPA detects rain more often compared to HOAPS-C nonmissing time steps, which may indicate that TMPA can detect rain showers with less than $2 \%$ rain coverage. However, mismatches in dataset time intervals result in a maximum overlap of only $4.5 \mathrm{~h}$ of the 6 -h periods of both data, which might to some extent explain the disagreement. Overall HOAPS-C is rather limited by sampling of SSM/I sensors, in particular in dry areas, whereas GPCP 1DD and TMPA are rather limited by algorithm assumptions.

The satellite data sources and retrieval-specific differences mainly affect the performance of the satellite climatologies. Even though the update to GPROF2004 greatly helped to relatively increase the rain occurrence in GPCP 1DD v1.2 during RICO by more than $50 \%$ compared to the predecessor v1.1, the current GPCP 1DD is still deficient with respect to (light) rain detection. GPCP 1DD predominantly detects those rain events with large area coverage while missing rain events with weak or smallscale showers. On the other hand, once rain is detected, GPCP 1DD overestimates the daily area-averaged rain rate against the S-Pol, as should be expected. Similar to GPCP 1DD, TMPA v7 features an absolute increase in rain occurrence of about $10 \%$ compared to the previous TMPA $v 6$ because of algorithm improvements in the use of AMSU data. With the S-Pol radar as a reference and under the assumption that rainfall during RICO follows the average rain conditions, TMPA performs best in terms of rain detection in an area dominated by light rain, followed by HOAPS-C and GPCP 1DD.

Acknowledgments. We acknowledge NASA Goddard Space Flight Center's Mesoscale Atmospheric Processes 
Laboratory, which processed the GPCP 1DD and the TMPA data, both extracted from http://precip.gsfc.nasa. gov, and the Satellite Application Facility on Climate Monitoring of the German Weather Service for processing HOAPS, downloaded from https://wui.cmsaf.eu. We thank the National Center for Atmospheric Research Earth Observing Laboratory for providing the S-Pol data and the Barbados Cloud Observatory for operating the MRR. We thank Axel Andersson and George Huffman for supporting our understanding of the dataset algorithms. Further, we thank Stephan Bakan who contributed critical comments and helpful ideas, as did three anonymous reviewers. We thank AngelaCheska Siongco and Matthias Brück for their help in improving the manuscript. The first author thanks Dallas Murphy and Jochem Marotzke for their inspiring scientific-writing course.

\section{REFERENCES}

Adler, R. F., and Coauthors, 2003: The Version-2 Global Precipitation Climatology Project (GPCP) monthly precipitation analysis (1979-present). J. Hydrometeor., 4, 1147-1167, doi:10.1175/1525-7541(2003)004<1147:TVGPCP > 2.0.CO;2.

Ahlgrimm, M., and R. Forbes, 2014: Improving the representation of low clouds and drizzle in the ECMWF model based on ARM observations from the Azores. Mon. Wea. Rev., 142, 668-685, doi:10.1175/MWR-D-13-00153.1.

Andersson, A., S. Bakan, and H. Graß1, 2010: Satellite derived precipitation and freshwater flux variability and its dependence on the North Atlantic oscillation. Tellus, 62A, 453468, doi:10.1111/j.1600-0870.2010.00458.x.

_, C. Klepp, K. Fennig, S. Bakan, H. Grassl, and J. Schulz, 2011: Evaluation of HOAPS-3 ocean surface freshwater flux components. J. Appl. Meteor. Climatol., 50, 379-398, doi:10.1175/ 2010JAMC2341.1.

Behrangi, A., M. Lebsock, S. Wong, and B. Lambrigtsen, 2012: On the quantification of oceanic rainfall using spaceborne sensors. J. Geophys. Res., 117, D20105, doi:10.1029/2012JD017979.

— , G. Stephens, R. F. Adler, G. J. Huffman, B. Lambrigtsen, and M. Lebsock, 2014: An update on the oceanic precipitation rate and its zonal distribution in light of advanced observations from space. J. Climate, 27, 3957-3965, doi:10.1175/JCLI-D-13-00679.1.

Brueck, M., L. Nuijens, and B. Stevens, 2015: On the seasonal and synoptic time-scale variability of the North Atlantic trade wind region and its low-level clouds. J. Atmos. Sci., doi:10.1175/ JAS-D-14-0054.1, in press.

Bumke, K., and J. Seltmann, 2012: Analysis of measured drop size spectra over land and sea. ISRN Meteor., 2012, 1-10, doi:10.5402 2012/296575.

Clemens, M., G. Peters, J. Seltmann, and P. Winkler, 2006: Timeheight evolution of measured raindrop size distributions. Proc. Fourth European Conf. on Radar in Meteorology and Hydrology, Barcelona, Spain, ERAD, 137-140. [Available online at http:// www.crahi.upc.edu/ERAD2006/proceedingsMask/00037.pdf.]

Doneaud, A., S. Ionescu-Niscov, D. L. Priegnitz, and P. L. Smith, 1984: The area-time integral as an indicator for convective rain volumes. J. Climate Appl. Meteor., 23, 555-561, doi:10.1175/1520-0450(1984)023<0555:TATIAA > 2.0.CO;2.
Ellis, T. D., T. L'Ecuyer, J. M. Haynes, and G. L. Stephens, 2009: How often does it rain over the global oceans? The perspective from CloudSat. Geophys. Res. Lett., 36, L03815, doi:10.1029/ 2008GL036728.

Fennig, K., A. Andersson, S. Bakan, C.-P. Klepp, and M. Schröder, cited 2012: Hamburg ocean atmosphere parameters and fluxes from satellite data-HOAPS 3.2-monthly means/6-hourly composites. Satellite Application Facility on Climate Monitoring (CM SAF), doi:10.5676/EUM_SAF_CM/ HOAPS/V001.

Field, P. R., and G. J. Shutts, 2009: Properties of normalised rainrate distributions in the tropical Pacific. Quart. J. Roy. Meteor. Soc., 135, 175-186, doi:10.1002/qj.365.

Hirota, N., Y. N. Takayabu, M. Watanabe, and M. Kimoto, 2011: Precipitation reproducibility over tropical oceans and its relationship to the double ITCZ problem in CMIP3 and MIROC5 climate models. J. Climate, 24, 4859-4873, doi:10.1175/ 2011JCLI4156.1.

Hou, A. Y., and Coauthors, 2014: The Global Precipitation Measurement (GPM) mission. Bull. Amer. Meteor. Soc., 95, 701722, doi:10.1175/BAMS-D-13-00164.1.

Houze, R. A., Jr., S. Brodzik, C. Schumacher, S. E. Yuter, and C. R. Williams, 2004: Uncertainties in oceanic radar rain maps at Kwajalein and implications for satellite validation. J. Appl. Meteor., 43, 1114-1132, doi:10.1175/1520-0450(2004)043<1114: UIORRM $>2.0 . \mathrm{CO} ; 2$.

Huffman, G. J., and D. T. Bolvin, cited 2013: Version 1.2 GPCP one-degree daily precipitation data set documentation. NASA Goddard Space Flight Center, 27 pp. [Available online at ftp:// rsd.gsfc.nasa.gov/pub/1dd-v1.2/1DD_v1.2_doc.pdf.]

— , and - , cited 2014: TRMM and other data precipitation data set documentation. NASA Goddard Space Flight Center, $42 \mathrm{pp}$. [Available online at ftp://precip.gsfc.nasa.gov/pub/ trmmdocs/3B42_3B43_doc.pdf.]

, R. F. Adler, M. M. Morrissey, D. T. Bolvin, S. Curtis, R. Joyce, B. McGavock, and J. Susskind, 2001: Global precipitation at one-degree daily resolution from multisatellite observations. J. Hydrometeor., 2, 36-50, doi:10.1175/ 1525-7541(2001)002<0036:GPAODD>2.0.CO;2.

_ and Coauthors, 2007: The TRMM Multisatellite Precipitation Analysis (TMPA): Quasi-global, multiyear, combined-sensor precipitation estimates at fine scales. J. Hydrometeor., 8, 38-55, doi:10.1175/JHM560.1.

Iguchi, T., T. Kozu, R. Meneghini, J. Awaka, and K. Okamoto, 2000: Rain-profiling algorithm for the TRMM Precipitation Radar. J. Appl. Meteor., 39, 2038-2052, doi:10.1175/ 1520-0450(2001)040<2038:RPAFTT>2.0.CO;2.

Keeler, R., J. Lutz, and J. Vivekanandan, 2000: S-pol: NCAR's polarimetric Doppler research radar. Proc. IEEE Geoscience and Remote Sensing Symp. 2000, Honolulu, HI, IEEE, 15701573, doi:10.1109/IGARSS.2000.857275.

Kidd, C., and G. Huffman, 2011: Global precipitation measurement. Meteor. Appl., 18, 334-353, doi:10.1002/met.284.

Klepp, C.-P., S. Bakan, and H. Graß1, 2003: Improvements of satellite-derived cyclonic rainfall over the North Atlantic. J. Climate, 16, 657-669, doi:10.1175/1520-0442(2003)016<0657: IOSDCR $>2.0 . \mathrm{CO} ; 2$.

_, K. Bumke, S. Bakan, and P. Bauer, 2010: Ground validation of oceanic snowfall detection in satellite climatologies during LOFZY. Tellus, 62A, 469-480, doi:10.1111/ j.1600-0870.2010.00459.x.

Knight, C. A., and L. J. Miller, 1998: Early radar echoes from small, warm cumulus: Bragg and hydrometeor scattering. J. Atmos. 
Sci., 55, 2974-2992, doi:10.1175/1520-0469(1998)055<2974: EREFSW $>2.0 . \mathrm{CO} ; 2$.

Kozu, T., and Coauthors, 2001: Development of precipitation radar onboard the Tropical Rainfall Measuring Mission (TRMM) satellite. IEEE Trans. Geosci. Remote Sens., 39, 102-116, doi:10.1109/36.898669.

Kummerow, C. D., and Coauthors, 2001: The evolution of the Goddard profiling algorithm (GPROF) for rainfall estimation from passive microwave sensors. J. Appl. Meteor., 40, 1801-1820, doi:10.1175/1520-0450(2001)040<1801: TEOTGP $>2.0 . \mathrm{CO} ; 2$.

- S. Ringerud, J. Crook, D. Randel, and W. Berg, 2011: An observationally generated a priori database for microwave rainfall retrievals. J. Atmos. Oceanic Technol., 28, 113-130, doi:10.1175/2010JTECHA1468.1.

Lau, K. M., and H. T. Wu, 2003: Warm rain processes over tropical oceans and climate implications. Geophys. Res. Lett., 30, 2290, doi:10.1029/2003GL018567.

Levizzani, V., P. Bauer, and F. J. Turk, 2007: Measuring Precipitation from Space: EURAINSAT and the Future. Advances in Global Change Research, Vol. 28, Springer, 722 pp.

Liu, C., and R. P. Allan, 2012: Multisatellite observed responses of precipitation and its extremes to interannual climate variability. J. Geophys. Res., 117, D03101, doi:10.1029/ 2011JD016568.

Lonitz, K., 2014: Susceptibility of trade wind cumulus clouds to precipitation. PhD thesis, Department of Geosciences, University of Hamburg, $117 \mathrm{pp}$.

METEK, 2009: MRR physical basics version 5.2.0.1. Meteorologische Messtechnik GmbH, 20 pp. [Available online at http://www.mpimet.mpg.de/fileadmin/atmosphaere/barbados/ Instrumentation/MRR-physical-basics_20090707.pdf.]

Mitrescu, C., T. L. Ecuyer, J. Haynes, S. Miller, and J. Turk, 2010: CloudSat precipitation profiling algorithm-Model description. J. Appl. Meteor. Climatol., 49, 991-1003, doi:10.1175/ 2009JAMC2181.1.

Nuijens, L., 2005: Estimating precipitation from radar observations in the trade-wind cumulus region. Master's thesis, Meteorology and Air Quality Section, Wageningen University, $46 \mathrm{pp}$.

, B. Stevens, and A. P. Siebesma, 2009: The environment of precipitating shallow cumulus convection. J. Atmos. Sci., 66, 1962-1979, doi:10.1175/2008JAS2841.1.

- I. Serikov, L. Hirsch, K. Lonitz, and B. Stevens, 2014: The distribution and variability of low-level cloud in the North Atlantic trades: Distribution and variability of low-level cloud in the trades. Quart. J. Roy. Meteor. Soc., 140, 2364 2374, doi:10.1002/qj.2307.

Olson, W. S., C. D. Kummerow, Y. Hong, and W.-K. Tao, 1999: Atmospheric latent heating distributions in the tropics derived from satellite passive microwave radiometer measurements. J. Appl. Meteor., 38, 633-664, doi:10.1175/1520-0450(1999)038<0633: ALHDIT $>2.0 . \mathrm{CO} ; 2$

Rauber, R. M., and Coauthors, 2007: Rain in shallow cumulus over the ocean: The RICO campaign. Bull. Amer. Meteor. Soc., 88, 1912-1928, doi:10.1175/BAMS-88-12-1912.

Sandu, I., B. Stevens, and R. Pincus, 2010: On the transitions in marine boundary layer cloudiness. Atmos. Chem. Phys., 10, 2377-2391, doi:10.5194/acp-10-2377-2010.

Short, D. A., and K. Nakamura, 2000: TRMM radar observations of shallow precipitation over the tropical oceans. J. Climate, 13, 4107-4124, doi:10.1175/1520-0442(2000)013<4107: TROOSP $>2.0 . \mathrm{CO} ; 2$.

Siongco, A. C., C. Hohenegger, and B. Stevens, 2015: The Atlantic ITCZ bias in CMIP5 models. Climate Dyn., doi:10.1007/ s00382-014-2366-3, in press.

Snodgrass, E. R., L. Di Girolamo, and R. M. Rauber, 2009: Precipitation characteristics of trade wind clouds during RICO derived from radar, satellite, and aircraft measurements. J. Appl. Meteor. Climatol., 48, 464-483, doi:10.1175/2008JAMC1946.1.

Stephens, G. L., and C. D. Kummerow, 2007: The remote sensing of clouds and precipitation from space: A review. J. Atmos. Sci., 64, 3742-3765, doi:10.1175/2006JAS2375.1.

_ - and Coauthors, 2010: Dreary state of precipitation in global models. J. Geophys. Res., 115, D24211, doi:10.1029/ 2010JD014532.

_ - and Coauthors, 2012: An update on Earth's energy balance in light of the latest global observations. Nat. Geosci., 5, 691-696, doi:10.1038/ngeo1580.

Suzuki, K., G. L. Stephens, S. C. van den Heever, and T. Y. Nakajima, 2011: Diagnosis of the warm rain process in cloud-resolving models using joint CloudSat and MODIS observations. J. Atmos. Sci., 68, 2655-2670, doi:10.1175/ JAS-D-10-05026.1.

Vila, D., C. Hernandez, R. Ferraro, and H. Semunegus, 2013: The performance of hydrological monthly products using SSM/ISSMI/S sensors. J. Hydrometeor., 14, 266-274, doi:10.1175/ JHM-D-12-056.1.

Wilson, J. W., C. A. Knight, S. A. Tessendorf, and C. Weeks, 2011 Polarimetric radar analysis of raindrop size variability in maritime and continental clouds. J. Appl. Meteor. Climatol., 50, 1970-1980, doi:10.1175/2011JAMC2683.1. 